\title{
Development of a Conformity Index To Assess Network Television News
}

$C B S$ best choice for viewer who sees only one newscast a day, but $A B C$ or NBC better for those using several sources.

- Numerous studies have sought a valid method for assessing quality in television news programs. This literature suggests that in the formulation and testing of a qualitative evaluation method, several conclusions are appropriate.

First, ratings are an inadequate measure of quality. By providing an estimate of the number of viewers in various demographic categories, ratings are useful to broadcasters to calculate rates for the sale of commercial time and advertisers to select programs as vehicles for commercials.' Nevertheless, because ratings, as Wulfemeyer writes, "are more of a popularity contest ... than a real measure of quality," 2 ratings must be rejected as a qualitative measure.

Second, direct use of any audiencegenerated data is questionable, if not inappropriate, in developing a qualitative measure. Wulfemeyer designed an index to gauge quality in local television news programs by assigning all segments in the newscasts into one of seven categories: commercials, issues, entertainment, banter, weather, unexpected events and sports. ${ }^{3}$ The

- David L. Jaffe is an associate professor in the School of Journalism and Mass Communication at the University of Oklahoma.

\footnotetext{
I Churchill L. Roberts and Sendra H. Dickson, "Assessing Quality in Local TV News," Journalism Quarterly. 61:392 (1984).

${ }^{2}$ K. Tim Wulfemeyer, "Developing and Testins Method for Asseasing Local TV Newscasts," Jowrnalism Qwarterly, 59:79 (1982).

Ibid., 80-81.
}

results of an audience preference survey were used to weight each category. Not surprisingly, the station highest on the "quality" index also was highest in the ratings, perhaps as Wulfemeyer speculated because the index "is based on the content preferences of the audience," as are the ratings. "In a somewhat similar study evaluating quality in local television newscasts, Roberts and Dickson noted "the consistency between the audience determined measures of quality and station ratings."'s The researchers concluded that audience data should be disqualified as a component of a measure of quality because of its inherent link to popularity which "may not be related to other indices of quality such as news substance." 6

Finally, the definition of quality in television news should be drawn from journalistic criteria. In rejecting the use of audience-generated data, Roberts and Dickson conclude that a more valid measure of quality should rely "solely on journalistic standards of excellence." " There are, of course, periodic judgments of quality from professional societies that use journalistic standards of excellence. Wulfemeyer argues against judgments of quality by these societies, however, noting that "the criteria ... are often vague ... and ... determinations are usually based on the quality of just one, or a limited number of newscasts." 8 In addition, consensus among professional judges seems limited. 9

\footnotetext{
4 Ibid., 81.

' Roberts and Dickson, 398.

Ibid.

'Ibid.

8 Wulfemeyer, 79.

Tbid.
} 
The purpose of this study was to construct and test a measurement instrument founded solely on journalistic standards that could serve as a means of assessing daily judgments by journalists and news editors in the preparation of programming for the three competing early evening network television newscasts.

Conformity, ${ }^{10}$ the common selection and presentation of news stories, was selected as the primary criterion to judge daily news programming decisions. In a study that examined the news judgment of the editors for the early evening television newscasts broadcast by $A B C, C B S$, and NBC by comparing news story segments, Fowler and Showalter found "significant agreement among network editors not only in their selection of news topics, but also in their treatment of stories." "I A study by Foote and Steele, which focused on conformity of the lead stories for the early evening television network newscasts, reported two network conformity $91 \%$ of the time and three network conformity $43 \%$ of the time. 12 In a study that examined the degree of conformity in news for one newspaper, two local television stations, and two local radio stations, Sasser and Russell claimed "disappointment" at the the "lack of consistency in emphasis and use of similar story topics." ${ }^{13}$ Nevertheless, the results showed the broadcast media conformity rate at about $50 \%$, although the newspaper rate was only $29.1 \% .^{14}$

One explanation for the relatively high level of conformity found in the preceding three studies might be explained in terms of the nature of news values. Since, as MacDougall notes, journalists and news editors "have similar criteria by which to determine the potential newsworthiness of

\footnotetext{
10 Atwater uses the term "consonance." Tony Atwater, "Consonance in Local Television News," Journal of Broadcastint \& Electronic Media, 30:467-472 (1986).

"Joseph S. Fowler and Stuart W. Showalter, "Evening Network News Selection: A Confirmation of News Judgment," Journalism Quarterly, 51:715 (1974).

12 Joe S. Foote and Michuel E. Steele, "Degree of Conformity in Lead Stories in Early Evening Network TV Newscasts," Jowrnalism Qwarterly, 63:21 (1986).

${ }^{13}$ Emery L. Sasser and John T. Russell, "The Fallacy of News Judgment," Journalism Quarterly, 49:284 (1972).

14 loid., 283.
}

thousands or millions of occurrences from which they make their selection each day," is a certain level of conformity would be expected. Hence, conformity is, in part, a function of common news judgment. Accordingly, conformity might be used as a means to assess gatekeeper decisions in the selection and emphasis of news stories, since it could be argued that the degree of conformity in a newscast is, in part, a measure of how other journalists and news editors of comparable standing judge the newsworthiness of a story. Thus, to the extent that conformity is a function of judgments of newsworthiness, the greater the conformity for a newscast, the greater the consensus or comprehensive judgment of newsworthiness among journalists; conversely, the less the conformity, the lower the comprehensive judgment.

A second explanation for conformity can be attributed to common organizational constraints in news operations. Epstein argues that the three "network news divisions operate under economic and political structures which impose a similar set of requisites and restraints." 16 Such conditions may also produce conformity. ${ }^{17}$ However, it can be argued that organizational constraints, like news values, are part of the decision-making process used in the determination and presentation of news programming. Accordingly, it seemed appropriate to collapse these two sources of conformity for the purpose of constructing an instrument to assess decisionmaking in the preparation of television news programs.

In this study, the conformity principle was employed as a rationale from which criteria were generated to evaluate network news story selection and emphasis.

\footnotetext{
${ }^{19}$ Curtis MacDougall, Interpretative Reporting, 6th ed., The Macmillan Company, New York, 1972, p. 39.

${ }^{16}$ Edward Jan Epstein, News from Nowhere (New York: Random House, 1973), p. 134.

${ }_{17}$ Technical access might also play a part. In a content aralysis of local television newscasts, Wulfemeyer concluded that "when no movins piatures were available ... stories ran considernbly shorter than they likely would have with video ection." K. Tim Wulfemeyer, "A Content Analysis of Local Television Newscasts: Answering the Critics," Journal of Broadcasting, 26:486 (1982).
} 


\section{Method}

The study was conducted in two stages. The first stage was the construction of an index to assess daily programming decisions affecting news story selection and emphasis in network television newscasts. ${ }^{18}$ Stage two included the collection of data and computation of the index rating.

Index construction. Three mutually exclusive categories of journalist decisionmaking were identified in which journalist and news editor performance could be measured. Each category was narrowly defined by one or more measurement criteria formulated to assess and measure the judgments of broadcast journalists and news editors based on judgments and decisions made by the journalists and news editors themselves.

Category 1. Comprehensive news judgment concerning important news events of the day, broadly defined as the evaluation of occurrences that "highlight the most important events and issues of the day," 19 and are judged so by broadcast and/or print journalists and news editors.

Criterion 1. Stories broadcast by all three commercial television networks on the same day and published subsequently by all three weekly national news magazines. 20

Criterion 2. Stories broadcast by all three commercial television networks on the same day and published subsequently by two weekly national news magazines.

Criterion 3. Failure of a commercial network to broadcast a story broadcast by the other two networks on the same day and published subsequently by all three weekly national news magazines.

Criterion 4. Failure of a commercial network to broadcast a story broadcast by the other two networks on the same day and published subsequently by two weekly national news magazines.

\footnotetext{
18 News programming can be evaluated in several areas: news story selection, eraphasis, accuracy, technical presentution, etc. This study was limited to the assessment of judgments in news story selection and emphasis.

19 Fowler and Showalter, op cit., p. 715.

20 The decision to use weekly national news magaines as a component in the construction of a stundard upon which to judge quality in network news was based on two factors: (1) in general, the magarines seek to serve the same news consumer constituency as the networks and (2) because the magavines are published once a week, news editors have the opportunity to employ greater perspective in judging the significance of news stories.
}

Category 2. Exclusive identification or anticipation of news stories ${ }^{21}$ judged as significant 22 by either broadcast or print journalists and news editors.

Criterion 5. Stories broadcast by one commercial network that are not broadcast by either of the other two commercial networks during the Monday through Friday period and published subsequently by all three weekly national news magazines.

Criterion 6. Stories broadcast by one commercial network that are not broadcast by either of the other two commercial networks during a Monday through Friday period and are published subsequently by two weekly national news magazines.

Criterion 7 . Stories broadcast by only one commercial television network on a day and then broadcast on a subsequent day by all three commercial networks.

Criterion 8 . Stories broadcast by only one commercial television network on a day and then broadcast on a subsequent day by two commercial networks.

Category 3. Investigative journalism, defined as "enterpriser stories" resulting "from initiative in identifying topics that otherwise would not be included in the newscasts." 23

Criterion 9. Stories broadcast by one commencial television network that are not broadcast by either of the other two commencial networks during a Monday through Friday period, and are not published in any of the three weekly national news magazines. A further requirement is the use of a correspondent in presenting the story. ${ }^{24}$

Although Criterion 9 describes a complete absence of news story conformity, it is appropriate to include this criterion in an evaluation of news story selection and emphasis because it measures initiative in investigative journalism, an important component of journalistic practice. Fowler and Showalter imply that a certain level of diversity in the news story menu is important when they note the difficulty in dis-

\footnotetext{
21 Raymond L. Carroll, "Content Values in TV News Programs In Small and Lange Markets," Journafism Qwarterly. 62:879 (1985).

22 Significance is defined as the subsequent decision of journalists to brondcast or publish the story.

${ }^{23}$ Carroll, op cit.

24 The requirement of correspondent involvement documents the investigative effort measured by criterion 9.
} 
tinguishing "between a healthy similarity and an unhealthy conformity in network news." 25

The definition of a news story developed by Fowler and Showalter was employed: "Any topic introduced by the anchorman coupled with any report or reports by other correspondents on the same topic and any concluding remarks by the anchorman." 26

The unit of measurement used in the study was seconds devoted to a story. Fowler and Showalter note that "since each newscast is allotted the same amount of time, the number of seconds ... provide[s] an indicator of its relative importance." 27 Only active reporting of a story was included. Anchor or reporter personal comments such as "good evening," "thank you," and "good night," and bumper shots and visuals of upcoming stories were not treated as part of a story.

Because the nine measurement criteria described several different levels of news story conformity among broadcast networks and weekly national news magazines, it was necessary to weight stories according to conformity levels. ${ }^{28}$ Full seconds per story were awarded for stories defined by criteria 1,5 , and 7 because those criteria require maximum conditions of conformity in either the broadcast (Criteria 1 and 7) or print (Criterion 5) media. Full seconds per story were awarded also for stories defined by Criterion 9 because a maximum condition of nonconformity was met. Full seconds were subtracted ${ }^{29}$ for stories defined by Criterion 3 because that criterion describes the failure of a network to broadcast news stories that, with the exception of that network, met the condition of maximum

\footnotetext{
${ }^{29}$ Fowler and Showaluer, op. cit., p. 715.

26 Ibid., 713.

27 Ibid., 714.

${ }^{28}$ Consistent with the notion that the higher the conformity level, the greater the comprehensive judement of newsworthi. ness, greater weight was given to stories with higher levels of news story conformity.

${ }^{2}$ Criteria 3 and 4 define conditions in which a network is not associated with the majority in which conformity occurs, therefore, seconds are subtracted from the network. Criteria 1 , $2,5,6,7$, and 8 define conditions in which aetwork is associated with the majority in which conformity occurs, therefore, seconds are awanded to the net work.
}

conformity. The number of seconds subtracted equaled the mean seconds devoted to the story by the remaining two broadcast networks (i.e., Network 2 story seconds + Network 3 story seconds $\div 2=$ seconds subtracted from Network 1).

Because news stories defined by Criteria 2,6 , and 8 describe a level of story conformity (i.e., conformity between 2 magazines instead of 3 for Criterion 6 , and conformity between 2 networks instead of 3 for Criteria 2 and 8 ) at the exact mid point along the range of conformity possibilities, ${ }^{30}$ one-half second (i.e., onehalf weight to correspond to the mid point) was awarded per story second. Similarly, for Criterion 4 , half seconds were subtracted because the criterion describes the failure of a network to broadcast news stories that, with the exception of that network, met conditions of mid point conformity (i.e., conformity between 2 news magazines instead of 3 ). The number of seconds subtracted equaled $50 \%$ of the mean seconds devoted to the story by the remaining two broadcast networks (i.e., Network 2 story seconds + Network 3 story seconds $\div 2 \times 50 \%=$ seconds subtracted from network 1).

The seconds accumulated by each network for the week were totaled. That total was divided by 60 to convert it to minutes, and, thereby, reduce it to a more manageable figure. The final figure for each network was expressed as a rating of the index-the Network News Index for Story Selection and Emphasis (NNISSE).

Data collection. The early evening television newscasts broadcast by $A B C, C B S$, and NBC during the week of November 16-20, and for November 23 and $24,1987^{31}$ were recorded on videotape. The news con-

\footnotetext{
${ }^{30}$ For example, three network or matyazine conformity corresponds to maximum conformity, no conformity corresponds to stories on one network or in one magazine only; therefore, story conformity of two networks or magazines is the half way point.

${ }^{31}$ News nonies for the Week of Nov. 16-20, 1987 only were included in the computation of the index rating. News stories on November 23 and 24, 1987 were coded to insure that all news stories broadcast during the woek of Nov. 16-20, 1987 defined by Criteria 7 and 8 were identified and included in the computation of the index natins. For example, a story broudcast by a network on Nov. 20 might qualify under criterion 7 if all three networks broadcast the story on Nov. 23.
} 
tent of each of the networks' programs for each of the seven evenings was then coded according to story topic and story length in seconds. ${ }^{32}$ Stories for each network were analyzed initially to identify those stories that were shared among all three or between any two networks for each evening and for the week. Stories not shared were also identified. Stories "were considered 'shared' if they relayed essentially the same information, although not necessarily with the same length or slant." 33 Infrequently, a story broadcast by one network contained news material peripheral to the primary story that was treated as a separate story by one or both of the other networks. On such occurrences, the peripheral news material was lifted out of the initial story and treated as a separate story for that network in order to preserve all cases of shared stories between and among networks; story times were adjusted accordingly. ${ }^{34}$

A similar content analysis was conducted for news stories published in the three weekly national news magazinesNewsweek, Time, and U.S. News and World Report-dated November 30, 1987, the issue that covered the week of television network newscast analysis. The stories were coded according to story topic. Shared stories among all three or between any two news magazines were identified.

The news stories for each network were then sorted according to the requirements of the nine measurement criteria. Only stories defined by the nine criteria were included. The index rating for each television network was then computed according to the procedure described previously.

\section{Results}

The NNISSE rating scores for each network are reported in Table 1 . The table displays the networks' scores for each of the nine measurement criteria, for each of

\footnotetext{
32 Because the nine messurement criteria mere so narrowly defined, it was deemed unnecessary to employ a panel of coders or test for intercoder reliability. News story lengths were verified by timing each story twice.

${ }^{33}$ Fowler and Showalter, od cit., p. 713.

34 Since the unit of mearurement wes "seconds devoted to a story" (not number of stories), this rearrangement permitted the identification of all occurrences of shared stories
}

the three categories, and as the index total. ${ }^{35}$

Category I-Comprehensive News Judgment. Although Criterion 1 suggests that each of the three networks devoted substantial newscast time to news presented by competing networks and the weekly national news magazines, it appears that CBS was more likely than the other two networks to broadcast news presented also by the other networks and the news magazines. Criteria 3 and 4 suggest that CBS was least likely to fail to broadcast news presented by competing networks and the news magazines. Accordingly, CBS achieved the highest rating score for Category 1.

Category II-Exclusive Identification/ Anticipation of Stories. Criteria 5 and 6 scores suggest that $\mathrm{ABC}$ and $\mathrm{NBC}$ each devoted more time than CBS to news material not broadcast by the competing two networks, but subsequently published by at least two news magazines.

According to Criterion 7, ABC devoted 238 seconds to news stories not broadcast by the other networks but on a succeeding evening addressed by all three networks. NBC devoted 183 seconds to similar news stories. CBS broadcast no such stories. With all but one of those stories it was possible for news editors to predict with some confidence that the stories would become significant in the future. On November 16, $\mathrm{ABC}$ alone devoted $140 \mathrm{sec}$ onds to a story on the Congressional Iran-Contra Report, scheduled for release two days later. All three networks subsequently devoted substantial news time to the story. Also on November 16, NBC alone broadcast a story that reported that negotiations would be extended in Geneva between the U.S. and the U.S.S.R. on reductions in medium range missiles. The next evening all three networks broadcast reports on the Geneva negotiations. On November 18, ABC alone broadcast a story on negotiations among members of the "White House-Congressional working group" in its effort to reach a compromise

\footnotetext{
35 Because the scores do not meet the assumptions for chi-square or analysis of variance tests, the scores are reported as descriptive data.
} 
TABLE 1

NNISSE Rating Scores

\begin{tabular}{|c|c|c|c|}
\hline \multicolumn{4}{|l|}{ Category I-Comprehensive News Judgment } \\
\hline \multicolumn{4}{|l|}{$\begin{array}{l}\text { Category I-Comprehensive News Judgment } \\
\text { Criterion } 1-\end{array}$} \\
\hline 3 net $/ 3$ mag conformity $(100 \%)$ & $2,064.00$ & $2,376.00$ & $2,184.00$ \\
\hline \multicolumn{4}{|l|}{ Criterion 2- } \\
\hline 2 net $/ 3$ mag conformity $(50 \%)$ & 169.50 & 164.00 & 247.50 \\
\hline \multicolumn{4}{|l|}{ Criterion 3- } \\
\hline Penalty, missing 2 net $/ 3$ mag conformity $(100 \%)$ & -209.00 & -30.50 & -213.00 \\
\hline \multicolumn{4}{|l|}{ Criterion 4- } \\
\hline Penalty, missing 2 net $/ 2$ mag conformity ( $50 \%$ ) & -11.50 & -66.00 & -54.75 \\
\hline Total & $2,013.00$ & $2,443.50$ & $2,163.75$ \\
\hline \multirow{2}{*}{\multicolumn{4}{|c|}{$\begin{array}{l}\text { Category II-Exclusive Story Identification/Anticipation } \\
\text { Criterion 5- }\end{array}$}} \\
\hline & & & \\
\hline 1 net only $/ 3$ mag conformity $(100 \%)$ & 130.00 & - & - \\
\hline \multicolumn{4}{|l|}{ Criterion 6- } \\
\hline 1 net only/2 mag conformity $(50 \%)$ & - & 6.00 & 94.00 \\
\hline \multicolumn{4}{|l|}{ Criterion $7-$} \\
\hline 1 net only prior to 3 net conformity $(100 \%)$ & 238.00 & - & 183.00 \\
\hline \multicolumn{4}{|l|}{ Criterion 8- } \\
\hline 1 net only prior to 2 net conformity $(50 \%)$ & - & - & - \\
\hline Total & 368.00 & 6.00 & 277.00 \\
\hline \multicolumn{4}{|l|}{$\begin{array}{l}\text { Category III-Investigative/Enterpriser Journalism } \\
\text { Criterion 9- }\end{array}$} \\
\hline $\begin{array}{l}1 \text { net only diversity }(100 \%) \\
\text { Total }\end{array}$ & $\begin{array}{l}1,661.00 \\
1,661.00\end{array}$ & $\begin{array}{l}1,458.00 \\
1,458.00\end{array}$ & $\begin{array}{l}1,543.00 \\
1,543.00\end{array}$ \\
\hline Total Score in Seconds & $4,042.00$ & $3,907.50$ & $3,983.75$ \\
\hline Rating Score in Minutes (Total Score $\div 60$ ) & 67.37 & 65.13 & 66.40 \\
\hline
\end{tabular}

\begin{tabular}{|c|c|}
\hline $\begin{array}{c}\mathrm{ABC} \\
\text { Criterion } \\
\text { score }\end{array}$ & $\begin{array}{c}\text { CBS } \\
\text { Criterion } \\
\text { score }\end{array}$ \\
\hline
\end{tabular}


scores in one category will increase the chances of higher scores in the other two categories, thereby lessening the differences in the total index score. For example, among the three networks, CBS had the highest score in category $I$ and the lowest score in categories II and III, and ABC scored lowest in category $I$ and highest in categories II and III.

\section{Discussion}

Before addressing the implications of this research, it is necessary to answer the question: Does NNISSE function as an instrument to gauge judgments of gatekeeper decision-making in news programming?

Any evaluation of excellence necessarily includes subjective components in the form of arbitrary rules. For example, in sports, the best team is the one that accumulates the most points in an arbitrarily determined number of innings or minutes in a quarter. With more innings or more minutes the outcome might be reversed. The nine measurement criteria and weighting system used in NNISSE, although not selected arbitrarily, were developed, thus incorporating a subjective component. Nevertheless, to the extent that conformity as measured by the nine criteria identifies judgments of journalists and news editors, it appears that NNISSE quantifies certain aspects of the professional performance of those responsible for preparing and presenting network television newscasts. NNISSE does not measure the universe of performance upon which excellence should be determined, but it does appear to measure several components of that universe.

The network scores for each of the three index categories may provide more useful information than the index rating score itself. In fact, although the objective of this research was to develop an index with a single numerical figure to rate journalist decision-making, it appears the index figure alone lacks utility. The results of the three index categories individually, however, seem to generate useful information for decision-making by viewers of television newscasts. For example, the scores in the first category, comprehensive news judgment, suggest that CBS was more likely than the other two networks to select and emphasize news that journalists and news editors in both broadcast and print media judged to be important news of the day and least likely to miss news judged important. Accordingly, for news consumers who want the most comprehensive package of network television news that covers the important events of the day, CBS would be the choice.

Similarly, since the scores in the second category, exclusive identification/anticipation of stories, suggest that $\mathrm{ABC}$ and NBC were more likely than CBS to identify, anticipate, and air stories that print and broadcast journalists later recognize as important news of the day, news consumers who wish to be forewarned and prepared for important news events would be better served by $A B C$ or NBC newscasts.

A comprehensive analysis of the scores can provide news viewers with specific decision-making information to be used in concert with personal news consumption habits. For example, for news consumers who rely on more than one source per day for news, $A B C$ or NBC would seem to be the choice. By watching, listening, or reading several news sources daily and watching either $\mathrm{ABC}$ or NBC newscasts, ${ }^{36}$ the news consumer is exposed through the ABC or NBC newscasts to a broader range of stories. Assuming an adequate mix of news sources, this multi source news consumer who views $\mathrm{ABC}$ or NBC newscasts would have an increased chance of being exposed to a greater variety of stories as well as the important news events of the day than the multi source news consumer who views CBS newscasts only. If, however, the opportunity for news consumption is limited to one newscast per day, and the news viewer wants the comprehensive news of the day, CBS would seem to be the best choice.

The scores in each of the three categories may serve also to reveal the news philosophies of the three network newscasts' decision-makers. The scores suggest

\footnotetext{
36 In many markets, the three newscasts are broadcast simultancously.
} 
that among the three networks, $A B C$ is the most committed and CBS the least committed to the presentation of investigative journalism efforts as well as the presentation of a broader range of events of the day. This permits ABC to present and emphasize stories that have a greater chance of becoming significant stories of the day (as judged by the conformity measure). This explanation can account for ABC's relatively high score and CBS's relatively low score in category II. ABC news and NBC news appear relatively more "predictive" of important news events, and CBS news appears relatively more "reactive" to important news events.

It must be remembered, however, that the results upon which all these conclusions are based were drawn from a one week rating period only. News programs for any one or all three of the networks may or may not have been representative.

For NNISSE to have utility for news viewer decision-making or to better understand the decision-making by network journalists and news editors, it should be computed regularly.

Refinements in NNISSE could increase its utility by providing more comparative data. According to Stempel, ${ }^{37}$ television news cannot be defined exclusively by $A B C, C B S$ and NBC, the Cable News Network (CNN) and PBS's MacNeilLehrer News Hour are significant and

\footnotetext{
${ }^{37}$ Guido H. Stempel IIl, "Topic and Story Choice of Five Network Newscasts," Journolism Qwarterly, 65:750-\$2 (1988).
}

comparatively different components in the national television news mix. Accordingly, by including elements of the early evening news programs of CNN and PBS in NNISSE, a more complete picture of journalist decision-making might be gleaned. Additionally, it might be worthwhile to explore additions to the index that would measure conformity in terms of content and treatment, as well as time devoted to a story. Also, it might be possible to divide each story into segments that yield a more precise identification and measurement of incidences of conformity. In addition, a 10th measurement criterion similarly based on conformity that addresses the serial order of stories in newscasts could be formulated.

Subsequent research could adapt NNISSE for application in local market television news. A Local Market News Index for Story Selection and Emphasis (LMNISSE) would substitute a varying mix (depending on the market) of newspaper(s), all news or all talk radio station(s)' newscasts for the three weekly national news magazines. As a result, there would be several variants of LMNISSE, depending on the nature of the television market. It is possible also to develop a variant of LMNISSE to assess journalist and news editor decisions in the selection and emphasis of stories in radio news by simply reversing the components in the criteria. Similarly, a variant of NNISSE could be used to assess gatekeeper decisions in news story selection and emphasis for the weekly national news magazines.

\section{$\longrightarrow$ \\ SURVIVABILITY OF DEFAMATION \\ (Continued from page 652)}

that no First Amendment issues were implicited in defamation survival actions. Both the courts also indicated that when it becomes a judicial issue, defamation of the dead is deserving of serious consideration as a logical extension of survivability of defamation. Clearly, the courts saw little distinction between defamation survival and defamation of the deceased. The possible chilling effect of the increasing recognition of survivability of defamation on press freedom has led to understandable criticism from the media. Although defamation survival actions have not been numerous in the past, an expansion of judicial and statutory recognition of defamation survivability and of defamation of the dead poses a threat to press freedom and continued public debate about issue of general concern. 